by organisation, or the structural endowments of the system, for their development and life's manifestation. The principle of life or nervous power is, in short, electricity, which is evolved from the blood at the extreme point of the circulation in the capillary vessels - the vessels of nutrition, assimilation, and secretion, under the excitement of caloric ; and in which vessels caloric is, at the same time, further evolved, for the perpetuation of the process, and is the result of the combination which is simultaneously effected between the oxygen of the blood derived from the air in respiration, with carbon, one of the constituents of the nutriment, received also into the blood from the stomach : and further, be it observed, that this evolution of heat or slow combustion of carbon is attended with an evolution of electricity, and is, in reality, the principal source of its production in the system ; for it is a fact, that whenever oxygen enters into chemical union with a body, electricity is evolved, as we see exemplified in the galvanic trough.

And thus the source of caloric and electricity, or vital temperature and nervous energy, being the chemical changes effected in the composition of the blood in the capillary vessels or organic structure; hence the general and equable temperature and vitality, or organic life of the system; the same in kind exactly as exists in vegetable creation.

In the animal creation there is, however, to the organic, superadded an animal life, connected with oryans of sense and volition, and infuenced through the medium of the brain and nerves. This is, however, superinduced by, and wholly dependent upon, the organic life. This leads me to observe, that the nervous system consists of brain and spinal marrow (the latter, however, being a mere prolongation of the former, I shall speak of both under one general termbrain) and nerves. The latter proceeding from, and being connected with the brain, falfil the office of conveyances of electricity and impressions from and to the brain; and to fulfil both these offices, there are consequently provided two sets of nerves, - - one of sensation, and the other of volition; the former proceeding from, and being connected with, every capillary vessel throughout the system, collect the electricity from its source, and transmit it and sensation to the brain,-the common receptacle and general depository of the system, as well as the seat of sensation. The electricity thus brought to the brain, it excites the various operations of the mind, or the organs of sense connected with it, to their respective functions; or is transmitted by the second class of nerves to the muscles of the body for their excitement, at the pleasure of volition; or is conveyed by another pair of nerves-the pneumogastric-to the lungs in aid of the respiratory function, and to the stomach in furtherance of that of digestion, as well as to the liver and the other abdominal organs connected with digestive and secretive processes, and associated in the formation and purification of the blood.

In addition, however, to those already enumerated, there is another set of nerves - the sympathetic, connected with the heart, stomach, and bowels, and all the rest of the involuntary or vital organs. These nerves are derived from twigs or fibres detached from every nerve of sensation, and are the importers of electricity, before it'communicates with the brain : hence the action of the heart in the circulation of the blood, and functions of digestion and assimilation in its formation, being primary in the scale of animal existence to the sensorial and voluntary functions, or those of the brain, are the first to receive an electrical supply, and the last to lose it, as long as any is generated in the capillary sys. tem; and hence it is that after the decapitation and apparent death of an animal, vitality in these organs is still maintained for a considerable time; in short, for as long a period as any oxygenated blood is furnished by the arterial trunks for chemical change and excitement of the capillary vessels. And thus it is the arteries are found empty after death; and further, that reoxygenating the blood by inflating the lungs, and imparting heat at the same time to the apparently dead, that resuscitation and animal life is so of ten restored.

In this brief display of the subject, I hope I shall have satisfied Mr. Brooks that there is such an influence as nervous energy; and for the facts and reasoning which I might have adduced in support of my explanation of its nature and source, I beg leave to refer him to the paper previously alluded to in your pages of the 4 th June, 1831. I am, Sir, your obedient servant,

Bath, August 24, 1841.

$$
\text { C. Searle, M.D. }
$$

\section{COLOURS OF THE SKIN IN MAN.}

\section{To the Editor of The Lancet.}

SIR :-In a letter on the origin of the different races of man, one of your correspondents has observed, "that the different colours of the skin are but the effects of living in different climates," as a proof of which he states that the Jews partake of various degrees of colour, according to the place they inhabit, and upon the coast of Malabar are jet black. It would be absurd to deny the vast influence that climate exercises upon the human race; but we must look for other causes in order to account for the differences which so strongly mark the varieties of man. A West Indian climate may act powerfully upon the skin of an European; yet the offspring of white parents 
in such latitude will be as fair as children born in Europe. An European climate will not make the offspring of negro parents white. As different races are found in the same country, their distinctions can only be explained by reference to their varied characters of organisation. For instance, in the islands of the Indian Sea, as well as in the Pacific, there are two varieties of the human species, one resembling the negro, the other, as Dr. Prichard says, more like the Indians of the continent. Such varieties cannot be traced to the influence of climate.

Although there is great variety of tempe. rature in New Holland, the Aborigines are dark in colour, and have curled and woolly hair like the negroes. Difference of colour in man is not the effect of climate. The Abyssinians situated near the equator are olivecoloured, and have long hair; whilst the Caffres, near the Cape of Good Hope, in a colder climate, are of the darkest colour. If climate influenced the colour of the human race, the inhabitants of the island of Madagascar ought to present an uniform appearance; on the contrary, they differ from each other as much as the Abyssinians do from the negroes. Although the continent of America includes every variety of climate, the American race presents an uniformity of character and appearance. The Esquimaux are not included; they are of Mongolian origin, and differ widely from the Americans.

When we find different races of men inhabiting the same country, and varying in physical, moral, and intellectual qualities, it must be something more than climate that has engendered the distinctions.

In Africa, Bruce met with a tribe supposed to be a remnant of the Vandals, having white and ruddy complexions, red hair, and blue eyes. In the Americas, as well as Asia and Africa, the European character is transmitted, with very little change, from generation to generation; in climates different from that of Africa, the descendants of negroes have not been altered by the power of climate. The Moors have lived in Africa since the seventh century, and have preserved the characters of their progenitors.

Your correspondent exultingly mentions some Jews on the Malabar coast, who have become black, but those Jews are not of pure blood; a portion of the tribe intermarried with the Hindoos, whose offspring are called black Jews, in contradistinction to those of pure blood, who are called white Jews. It was breeding, not climate, that altered the Malabar Jew. For ages the Jews have been scattered over the earth, and exposed to every vicissitude of climate; still they maintain the colour and features that are characteristic of their race. The differences of organisation in the various races of man cannot be accounted for by the operation of external causes. Yours, \&c.

Boston, Sept. 1, 1811.

F. Snaith, M.D.

Secondaries' Court, Basinghall-street, August 13.-(Before Mr. Secondary Potter.) -Riehmond v. Dr. Mantell.-This was an action against the defendant, the celebrated surgeon and geologist, to recover the sum of $7 l$. $11 \mathrm{~s} .3 \mathrm{~d}$., for medicines supplied by the plaintiff, a druggist, at Clapham. The defendant pleaded that he was not indebted. Mr. Thomas appeared for the plaintif, and Mr. Gurney for the defence. It appeared by the evidence that the action was brought for medicines supplied between November, 1838, and March, 1839, and a witness was called to prove the delivery from time to time during the period above stated. The bill did not include any charge for medicine after 1838, except such as a set-off was pleaded to, for professional attendance on the plaintiff and his housekeeper. Mr. Gurney, for the defendant, submitted that the demand of the plaintiff had been discharged up to the end of the year 1838, and a receipt was put in to prove that fact; and since that time Dr. Mantell had rendered his professional services, which the jury would find was an ample set-off for any charges after that time. Mr. Lee, assistant to Dr. Mantell, proved the payment of the plaintiff's bill up to the end of the year 1838, and remembered the doctor's professional visits to the plaintiff. The medicines constituting the present demand appeared to have been charged for after Dr. Mantell had established a surgery of his own, and at his own residence, in October, 1838. Mr. Thomas replied, and contended that the case established by him on behalf of the plaintiff had been in no way shaken by the evidence on the other side. The Secondary then went over the evidence. The Jury, after a short consultation, returned a verdict for the defendant. Not content with this decision, the plaintiff, who had already protracted the action, to amend particulars, applied on the following Tuesday for an arrest of proceedings, and the cause was argued by counsel before the judge, who finally dismissed the case, refusing to grant the plaintiff's application. It should be stated that the defendant who objected not only to the correctness of the items, but also to the exorbitant charges of many of the drugs, had offered on the first application to settle the affair by a reference, but this the plaintiff refused. During the pending of the action four different claims were made, each varying from the others, both in regard to the amount as well as the period at which the debt was stated to have been contracted. One of the claims being dated from the year 1837, when the defendant was not living ai Clapham, Weekly Paper. 